\title{
More Facts that Isomorphism Cannot Explain
}

\author{
Vincenzo Moscati \\ Siena University
}

\author{
Andrea Gualmini \\ Utrecht University
}

\section{Introduction}

A phenomenon which has attracted considerable attention by researchers in child language is the interaction between quantifiers and negation. Much work on this topic starts from the findings documented by Musolino (1998). That study included a series of experiments investigating English-speaking children's interpretation of sentences like the following.

(1) Every horse didn't jump over the fence

(2) The detective didn't find some guys

(3) The detective didn't find two guys

Each of the sentences above contains two operators: negation and a quantified noun phrase. This yields two logically possible scope assignments for each sentence. To illustrate, (1) is ambiguous between the two interpretations listed below.

(4) Every horse is such that it did not jump over the fence

$\forall \mathrm{x}$ [horse (x) $\rightarrow \neg$ jump over the fence (x)]

'for every $\mathrm{x}$, if $\mathrm{x}$ is a horse then $\mathrm{x}$ did not jump over the fence'

(5) Not every horse jumped over the fence

$\neg \forall \mathrm{x}$ [horse (x) $\rightarrow$ jump over the fence (x)]

'it is not the case that for every $\mathrm{x}$, if $\mathrm{x}$ is a horse then $\mathrm{x}$ jumped over the fence'

The two interpretations of (1) listed in (4) and (5) result from the relative scope assignment to negation and every, as suggested by the order of the operators $\neg$ and $\forall$ in the logical formulae. In the semantic literature, the interpretation in (4) is

We would like to thank Eva Dobler, Marc Garellek, Michelle St-Amour and Eva Sokol for their help in conducting the experiments. We also thank the children, administrators and parents at Children's Corner, CPE McGill, Playskool, SSMU and YMCA Westmount daycares in Montreal and at the Scuola Materna S.Benedetto in Siena, where the experiments have been conducted. The research reported in this paper was partially funded by a McGill VP-Internal research grant and a grant from McGill's Arts Undergraduate Society. Andrea Gualmini is currently supported by a VIDI fellowship from the Netherlands Organization for Scientific Research (NWO) and Utrecht University. 
referred to as the 'surface scope' or 'isomorphic' interpretation of (1), while (5) is referred to as the 'inverse scope' or 'non-isomorphic' interpretation of (1). This is because in (4) the scope bearing elements every and not are interpreted in the same order with which they appear in the overt syntax, whereas in (5) they are interpreted in the opposite order.

The research question that Musolino (1998) and others have addressed is whether young children are capable of accessing both the surface scope and the inverse scope interpretation of sentences containing negation and another scopebearing element. The experimental evidence collected by Musolino (1998) suggests that this is not the case. In fact, the evidence suggests that, for all the constructions in (1), (2) and (3), 4- and 5-year-old children consistently resort to their surface scope interpretations. This finding led Musolino (1998) to propose the Observation of Isomorphism, the claim that children's semantic scope coincides with overt syntactic scope.

More recent studies have led to an important refinement of the picture suggested by Musolino's findings. In particular, recent studies have shown that children's interpretation of sentences like (1), (2) and (3) is affected by the context. For instance, Gualmini (2004) has shown that, in a context in which the Troll is expected to deliver all the relevant pizzas, children select the inverse scope interpretation of (6).

(6) The Troll didn't deliver some pizzas

In the same vein, Gualmini (2004) demonstrated that children are perfectly capable of assigning wide scope to the indefinite some with sentences such as (7), and Gualmini (in press) has shown that the same is true for Italian-speaking children.

\section{Every farmer didn't clean some animal}

Furthermore, Gualmini, Hacquard, Hulsey and Fox (2005) have recently shown that the same contextual maneuver discovered by Gualmini (2004) leads children to select the inverse scope interpretation of sentences comparable to (1) and (3) to a higher extent than observed in previous literature. Finally, Musolino and Lidz (2006) report that children select the inverse scope interpretation of (8) to a larger extent than they did for (1).

(8) Every horse jumped over the log, but every horse didn't jump over the fence.

The finding that children's behavior changes systematically across contexts poses a challenge for the original view of Isomorphism, especially since these studies focused on the exact same sentences which, according to Musolino, were predicted to be interpreted exclusively on their surface scope interpretation.

Having established that children are capable of accessing inverse scope interpretations, however, the question remains whether surface scope 
interpretations and inverse scope interpretations have equal status in child language. One view, proposed by Hulsey, Hacquard, Fox and Gualmini (2004) argues that children do not have any default preference for surface scope interpretations, but are rather guided by discourse relevance. A different view, proposed by Musolino and Lidz (2006), claims that surface scope interpretations are indeed special. On this view, children's behavior follows from a preference for surface scope interpretations and a preference for true interpretations. In particular, the former factor is supposed to take precedence over the latter, in order to explain the fact that children often select false surface scope interpretations over true inverse scope interpretations.

An interesting aspect of the current debate is that the focus is on the interaction between negation and quantified noun phrases (but see Krämer 2000 for an important exception). This is somewhat surprising, given that both accounts described above also make predictions for sentences containing other scope bearing elements. For example, it seems appropriate to expand the empirical basis of the debate by looking at children's interpretation of sentences containing negation and a modal operator. This is exactly what we intend to do.

\section{Modals and Negation across Languages}

In this section we introduce the relevant facts about sentences containing negation and a modal operator in adult English and adult Italian. Both languages present sentences which adults prefer to interpret on their inverse scope interpretation. To illustrate, consider the sentence below.

The lion cannot be in the same cage as the tiger

As the morphology suggests, the verbal form cannot can be decomposed into the modal operator can $(\diamond)$ and negation $(\neg)$. Interestingly, these two scope-bearing elements are not interpreted according to the surface syntax. In other words, the preferred interpretation of (9) is the interpretation paraphrased in (10), whereas the interpretation paraphrased in (11) is largely dis-preferred, if at all available

(10) It is not the case that the lion can be in the same cage as the tiger $\neg>\diamond$

(11) It is possible that the lion not be in the same cage as the tiger $\diamond>\neg$

In Italian, we can express the logical equivalent of (10) both using the modal verb 'potere' $(\diamond)$ and 'dovere' $($ ) in combination with sentential negation. Due to the parametric difference in the position of negation, the latter choice gives rise to an inverse scope configuration where negation c-commands the modal verb in the overt syntax but it is interpreted within the scope of the modal operator. To illustrate, consider (12) and its two possible interpretations in (13) and (14): 
(12) Il leone non deve stare nella stessa gabbia con la tigre

'The lion not must be in the same cage with the tiger'

(13) It is not the case that the lion must be in the tiger's cage

$\neg>$

(14) It necessary that the lion not be in the tiger's cage

Interpretation (14), which is logically equivalent to (10), is the preferred interpretation of (12). It is interesting to observe that the differences between English and Italian regarding the choice of the modal auxiliary and the relative position of negation end up canceling each other out: (9) and (12) express the same proposition under their inverse scope interpretation. In fact, from the perspective of the syntax-semantics mapping, we observe that both languages make use of an inverse scope mapping to convey the proposition preferred by adults. Thus, the question is whether English- and Italian-speaking children can make use of the covert movement operation that is required by the adult interpretation of the relevant sentences. ${ }^{1}$

As we saw above, the view proposed by Musolino and Lidz (2006) claims that children's behavior is ultimately dictated by two factors: a preference for surface scope interpretations and a preference for true interpretations. When it comes to sentences like (9) and (12), this amounts to claiming that children should interpret the relevant sentences on their surface scope interpretation, especially when the surface scope interpretation allows them to say 'yes.' To evaluate this claim, we turn to the laboratory.

\section{Experimental Design}

In this section, we present the results of two experiments investigating children's interpretation of sentences containing negation and a modal operator.

\subsection{Experiment I}

In this section we report the results of an experiment with English-speaking children. The purpose of the experiment is to investigate how children interpret sentences containing the modal form cannot. Recall (9), and its logically possible readings in (10) and (11), repeated below.

(9) The lion cannot be in the same cage as the tiger

(10) It is not the case that the lion can be in the same cage as the tiger $\neg>\diamond$

(11) It is possible that the lion not be in the same cage as the tiger $\quad \diamond>\neg$

\footnotetext{
${ }^{1}$ In this paper we assume that it is the negative operator which covertly moves in order to generate the inverse scope readings (Moscati 2006, 2007). However, nothing changes if one considers the auxiliary as the element which undergoes covert movement.
} 
The experiment took the form of questions after stories. First, children were presented with the instruction in (9) in the context of a story. In the story, children were told that Dora was working at the zoo. At the zoo, there were two cages, one cage containing a tiger and one cage containing a giraffe. Dora's job was to put two other animals into the cages, a hippo and a lion, and the instruction she had received was (9). During the experiment, we told children that Dora had forgotten what the instructions were and that she would ask them for some help. Then Dora asked children the pre-test question in (15) and then the question in (16).

(15) Can I put the hippo with the tiger?

(16) Can I put the lion with the tiger?

Let us spell out the reason for the pre-test question. If children interpret the target sentence on its inverse scope interpretation (10), then they know that in the actual world the lion should not be in the same cage as the tiger. However, if they interpret the target sentence on its surface scope interpretation (11), then they know that it is possible for the lion not to be in the same cage as the tiger, but this is compatible both with a 'yes' and a 'no' answer to (16). Thus, the surface scope interpretation of (9) under-determines whether the lion could be placed with the tiger in the actual world. The problem is that we do not know how children respond to questions that are under-determined by their state of knowledge. However, given that the inverse scope interpretation of the target instruction is associated with a 'no' answer to the question, it is essential that the surface scope interpretation be associated with a 'yes' answer. In short, it is important to ensure that children say 'yes,' when they are presented with an under-determined question. This is the reason for the question in (15). If a child answers 'yes' to (15), then we can assume that that child will answer 'yes' to an under-determined question. By contrast, if a child answers 'no' to a question like (15), then we can't assume that that child would answer affirmatively to a question, when both the affirmative answer and the negative answer are compatible with his state of knowledge. In this case, it would be appropriate to exclude that trial from the experiment.

Let us now turn to the results. 15 English-speaking children (age 4;0 - 5;5, mean 4 ;9) participated in the experiment. Each child was presented with 4 questions like (15). Out of the resulting 60 questions, children answered 'yes' 47 times $(78.3 \%)$. On those trials, children were than asked questions like (16), and out of those 47 trials said 'no' 43 times $(91.4 \%) .^{2}$ In other words, children who respond 'yes' to under-determined questions, respond 'no' the question in (16). We interpret this result as suggesting that children do not treat (16) as an underdetermined question. In fact, if children interpreted (9) on its surface scope interpretation, their state of knowledge would warrant both an affirmative answer and a negative answer to the question in (16). Thus, children would be expected to

\footnotetext{
${ }^{2}$ If we consider also the trials on which children had failed the pre-test, the numbers don't change: children answered 'no' to (16) 55 times out $60(91.6 \%)$.
} 
answer 'yes,' just like in the case of questions like (15). This is not what happened, however. Children have constructed an interpretation of the instruction in (9) that leads them to give a negative answer to the question in (16), and that interpretation is the same inverse scope interpretation that adults would select. Crucially, the experimental results do not seem to be epiphenomenal on the choice of modal or on the position of negation in English since a variation of those factors doesn't affect the interpretation of the sentence, as we will see in the next experiment.

\subsection{Experiment II}

A second experiment was conducted with Italian-speaking children in order to evaluate whether the results obtained in English are due to some special property of the English modal system but they reflect a genuine property of early grammar: the possibility of accessing inverse scope readings with modal auxiliaries and negation. We told 17 Italian-speaking children (age 4;5 - 6;0, mean 5;3) 4 stories similar to the ones in Experiment I. But this time, during each story, the character received an instruction containing the modal verb dovere 'must' instead of potere 'can.' In one story, analogous to the one previously illustrated, Dora received the following instruction:

(12) Il leone non deve stare nella stessa gabbia con la tigre

'The lion not must be in the same cage with the tiger'

(13) It is not the case that the lion must be in the tiger's cage $\neg>$

(14) It is necessary that the lion not be in the tiger's cage $>\neg$

Recall that a possible reading for sentence (12) is given in (14) and that it expresses the same meaning of the English sentence (9), namely the impossibility for the lion to be together with the tiger. Given that the two sentences are truthconditionally equivalent under their inverse scope reading and that the storycontext has been left unchanged, we can use the same pre-test and test question used in Experiment I:

(17) L'ippopotamo può stare nella gabbia della tigre?

'Can the hippo be in the tiger's cage?'

(18) Il leone può stare nella gabbia con la tigre?

'Can the lion be in the tiger's cage?'

The results are that Italian children answered 'yes' to the pre-test question 59 times out of $68(86.7 \%)$ and among those trials, like their English-speaking peers, they also answered 'no' 52 times out of $56(93.2 \%)$ to the test question (e.g., 
(18). ${ }^{3}$ As Table 1 shows, the results obtained from Italian-speaking children are similar to the ones found with English-speaking children:

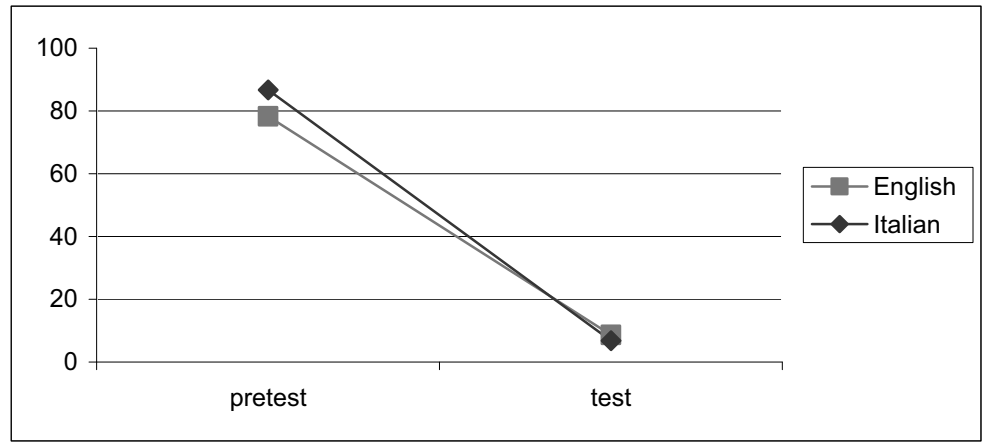

Table 1. Affirmative answers of Italian- and English-speaking children to the pretest and test questions.

Looking at Table 1, first we observe that no difference is found regarding the rate of affirmative answers to the contextually underspecified question asked in the pre-test condition and that both Italian- and English-speaking children answer 'yes' when the context allows them to do so. Second, and more interestingly, both populations of children give a negative answer to the test question, regardless of the differences in the modal used and in the position of negation in the instruction. These results strongly suggest that the variation of these two factors doesn't have any effect on the computation of the truth-conditions of the target sentences (9) and (12) and that surface c-command does not dictate the semantic interpretation.

We would like to end with a comment on one difference between Italianspeaking children and Italian-speaking adults, which we must leave for future research. It has to be noticed that, while in English the inverse scope reading appears to be the only possible - or strongly favored - option, in adult Italian the surface scope reading is also possible. This means that whatever mechanism rules out the surface scope interpretation in English is not active in Italian. Nevertheless, the inverse scope reading was preferred by the Italian-speaking children in Experiment II, suggesting that the preference for the inverse scope reading is not determined by some special (i.e. polarity) property of the modal can.

\footnotetext{
${ }^{3}$ The answers of one child were discarded. This child answered 3 times 'yes' to the target question but when she was asked for explanations she answered by saying 'I say yes even if it was stated that the lion cannot.' This follow up suggested that she interpreted the target sentence under the inverse scope reading. Being the answers and the motivation in contrast, we decided to exclude those answers from the count.
} 


\section{Conclusion}

Let us sum up. In this paper, we addressed the current debate on children's interpretation of scopally ambiguous sentences by considering sentences containing negation and modal operators. The results show that English- and Italian-speaking children interpret (9) on its inverse scope interpretation. This finding poses a challenge to the view defended by Musolino and Lidz (2006), which derives children's behavior from a putative preference for surface scope from children's failure to re-analyze.

\section{References}

Cinque, Guglielmo: 1999, Adverbs and Functional Heads: A Cross-linguistic Perspective, Oxford University Press, Oxford.

von Fintel, Kai and Sabine Iatridou: 2003, 'Epistemic Containment' Linguistic Inquiry 34, 173-198.

Gualmini, Andrea: 2004, The Ups and Downs of Child Language, Routledge, New York.

Gualmini, Andrea: in press. 'Mechanisms of Scope Resolution in Child Italian' in S. Baauw, F. Drijkoningen and M. Pinto (eds.) Romance Languages and Linguistic Theory 2005, John Benjamins Publishing Company, Amsterdam/Philadelphia.

Gualmini, Andrea, Valentine Hacquard, Sarah Hulsey and Danny Fox: 2005, 'Beyond the Surface of Child Language', paper presented at the Annual Meeting of the Linguistic Society of America, San Francisco, CA.

Hulsey, Sarah, Valentine Hacquard, Danny Fox, and Andrea Gualmini: 2004, 'The Question-Answer Requirement and Scope Assignment', in A. Csirmaz, A. Gualmini and A. Nevins (eds.) Plato's Problem: Problems in Language Acquisition, 71-90. MITWPL, Cambridge, Mass.

Krämer, Irene: 2000, Interpreting Indefinites, Ponsen \& Looijen, Wageningen.

Moscati, Vincenzo: 2007, 'Negative Chains and LF Negation Raising', Proceedings of XXXIII Incontro di Grammatica Generativa, Università di Bologna.

Moscati, Vincenzo: 2006, The Scope of Negation. Doctoral Dissertation, Università degli Studi di Siena.

Musolino, Julien: 1998, Universal Grammar and the Acquisition of Semantic Knowledge, Doctoral Dissertation, University of Maryland at College Park.

Musolino, Julien and Lidz, Jeffrey: 2006, 'Why Children Aren't Universally Successful with Quantification', Linguistics 44, 817-852.

Rizzi, Luigi: 1982, Issues in Italian Syntax, Foris, Dordrecht. 